Sir,

\section{Web-based information on glaucoma}

Glaucoma is the fourth most common search term in ophthalmology. ${ }^{1}$ In western countries over $50 \%$ of patients use Internet for information. ${ }^{2}$ In oculoplastic surgery the quality of web-based information has been investigated using an instrument published in the Journal of the American Medical Association (JAMA) which comprises four criteria: (1) authorship; (2) attribution of sources; (3) disclosure, for example, duality of interest declarations; (4) time records for posting information. ${ }^{3,4}$ These yield a score from 0 to a maximum of 4 .

We have studied and presented outcomes for glaucoma using this instrument applied to the Google search engine. ${ }^{5}$

Keyword expansion of the search term 'glaucoma' showed it to be by far the most popular search term on the subject. The first five pages of 'Google' were analysed for this search term over a 12-month period yielding 50 websites (10 per page). ${ }^{5}$ This is as users of the Internet are much less likely to browse beyond the first five pages of a search engine. ${ }^{3}$ 'Pay per click' advertising links were ignored. Many websites were found to be of poor quality$28 \%$ scored zero JAMA points; $24 \%$ scored one point; $6 \%$ scored two points; $38 \%$ scored three points and $4 \%$ scored four points. An online encyclopedia was the most visited website (and scored three points). Charities were the most popular type of websites on page one of the Google search. NHS hospitals scored uniformly well (mean 3, mode 3, median 3). Peer-reviewed journals scored best.

'Medipedias' (online encylopedias) varied in quality and displayed a bimodal peak (0 and 3). The websites of professional bodies and charities scored almost zero (mean 0.3 , median 0 , mode 0 and mean 0.25 , median 0 , mode 0 , respectively). Youtube videos scored poorly.

The relative popularity of patient-friendly websites suggests that more patients are turning to the Internet to understand their glaucoma. This is useful as it may help busy clinicians explaining the need for compliance with treatment. However the quality of information on the Internet remains objectively poor in most cases. The 'Internet factor' may increasingly become important in understanding glaucoma outcomes.

\section{Conflict of interest}

The authors declare no conflict of interest.

\section{Acknowledgements}

This work was awarded a travel grant for the best work presented in the Glaucoma Section of the European Association of Vision and Eye Research (EVER).

\section{References}

1 Leffler CT, Davenport B, Chan D. Frequency and seasonal variation of ophthalmology-related internet searches. Can J Ophthalmol 2010; 45(3): 274-279.

2 Saithna A, Ajayi OO, Davis ET. The quality of Internet sites providing information relating to hip resurfacing. Surgeon 2008; 6: 85-87.

3 Zaidi FH, Jones CA. Informing patients: oculoplastic surgery and the internet. Eye (Lond) 2009; 23(11): 2090-2093.

4 Silberg WM, Lundberg GD, Musacchio RA. Assessing, controlling, and assuring the quality of medical information on the Internet: Caveant lector et viewor-Let the reader and viewer beware. JAMA 1997; 277: 1244-1245.

5 Zaidi FH, Ansari E. Glaucoma and the Internet. Acta Ophthalmologica 88, s246, 0, September 2010. Special Issue: Abstracts from the 2010 European Association for Vision and Eye Research Conference. Awarded travel grant for the best work presented in the Glaucoma Section of the European Association of Vision and Eye Research (EVER).

FH Zaidi $^{1}$ and E Ansari ${ }^{1,2}$

${ }^{1}$ Maidstone and Tunbridge Wells NHS Trust, Hermitage Lane, Maidstone, Kent ME16 9QQ, UK

${ }^{2}$ Department of Physical sciences, Ingram Building, University of Kent, Canterbury CT2 7NH, UK

E-mail: fhz12@hotmail.com

Eye (2015) 29, 1396; doi:10.1038/eye.2015.52; published online 15 May 2015 